\title{
A lesson in student chapters
}

\author{
By participating in activities organized by professional societies, PhD students can enrich their skills and \\ extend their professional network, beyond what they can achieve in the lab, Yi-Hsin Lin explains.
}

G raduate students spend most of their time in the lab doing research and preparing for their dissertation, but it is also important that they find time for professional development and that they extend their professional network beyond their own research group, department and university. Important vehicles in this regard are professional societies, which in the field of optics and photonics, include the International Society for Optics and Photonics (SPIE) and the Optical Society of America (OSA). By joining them, students can enjoy benefits such as scholarships, online access to journals, and discounts on travelling to and attending conferences. But beyond these tangible perks, societies - and student chapters in particular - also offer a range of activities that are designed to help students grow, connect with other researchers and make an impact in society.

As a graduate student in the College of Optics and Photonics (CREOL) at the University of Central Florida, I served as vice president of the SPIE Student Chapter there, president of the Orlando Chapter of the IEEE Lasers and Electro-Optics Society, and associated vice-president of CREOL Association of Optics Students. After graduation, I joined the faculty of the National Chiao Tung University (NCTU), Taiwan, where I volunteer to help at the local SPIE NCTU chapter. Here, I would like to explain the valuable role that student chapters has played in my career, and show why more students should step out of their lab and explore the opportunities these chapters have to offer.

The most established student chapters organize yearly activities based on the needs and interests of the members. These activities include student meetings, voluntary teaching of school students or undergraduates, lab tours, simple handson demonstrations, informal lectures, special training courses and tours of local industrial labs. Officers are elected by student members and are responsible for liaising with professional societies. If a university does not have student chapters, you can submit a petition to start a new one.
Student chapters can apply for activity grants from professional societies. For example, during my time at the student chapter at CREOL, the SPIE sponsored a project to design various types of display, including an electrically switchable display made of polymer-dispersed liquid crystals, a hologram display, a nonlinear optics display and a fountain waveguide display; all of the resulting devices were then located in the lobby of the department, along with explanatory outreach material. This material was predominantly for the benefit of undergraduate students and lay visitors. The members of the student chapter had the chance to explain how the displays functioned to people with less expertise than them, and receive immediate feedback on their communication skills. Activities such as this are designed to instil self-confidence and encourage the students to get involved with society at large, while, hopefully, inspiring others to become scientists.

The opportunity I had to inspire others is, in fact, one of my fondest memories from my time with the student chapter at CREOL. We received a request from a school teacher who asked for a tour of the optical display project for her students. During the demonstrations of the displays, the pupils, most of them from poor backgrounds, showed genuine curiosity and asked numerous naive, yet insightful, questions. I had a feeling that the visit gave them the opportunity to think about things in a completely different way and perhaps to dream big about their future. It was a delightful and touching experience, which emphasized to me that, even as a $\mathrm{PhD}$ student, my scientific knowledge could be a powerful tool for inspiring others.

Through exchanges with other student chapters and other similar activities, members have the opportunity to get to know each other both professionally and personally, independent from the usual professor-centered set-up of a research group. Most student chapters also arrange informal lectures specifically tailored for $\mathrm{PhD}$ students. The lectures are sponsored by a professional society who suggest a list of distinguished lecturers to invite. As one of the officers, I helped to host several of these, and from experience I know that student members are always eager for face-to-face connections and scientific discussions with established researchers. I have to admit though that organizing such lectures does take attention away from lab work, especially when you are approaching the end of your PhD. However, the scientific insights that can be gained by talking directly to world-renowned scientists (most of them revered only as a name in a textbook or a landmark paper) definitely makes it worth the effort.

After graduation, there are alumni programmes that can aid academic growth, and many members return to the SPIE chapters as mentors, facilitators, conference committee members and as volunteers at various levels. As a faculty member, I now contribute as a consultant to the SPIE NCTU chapter. Recent activities include organizing tours of the nanotechnology facilities of Taiwan, holding a brainstorming session on how to make undergraduates excited about specific research projects at NCTU, and planning hands-on demonstrations of practical applications developed at the University, such as an electrically tunable polymeric ophthalmic lens. The SPIE NCTU chapter is also planning events to celebrate the UNESCO (United Nations Educational, Scientific and Cultural Organization) International Year of Light in 2015, and we intend to collaborate with the National Museum of Natural Science in Taiwan and design special courses and demonstrations for school children.

Participation in student chapters can help students develop leadership skills and work on their professional goals - be it to become a professor, an entrepreneur, or something else, but more importantly to help them follow the wish of Albert Einstein: "Try to become not a man of success, but try rather to become a man of value."

\footnotetext{
YI-HSIN LIN is an associate professor in the Department of Photonics, National Chiao Tung University, 1001 Ta Hsueh Road, Hsinchu 30010, Taiwan. e-mail: yilin@mail.nctu.edu.tw
} 